NASA Technical Memorañdum 101492

\title{
DIRECT SIMULATION OF THREE - DIMENSIONAL FLOW ABOUT THE AFE VEHICLE AT HIGH ALTITUDES
}

M. Cevdet Celenligil

James N. Moss

Graeme A. Bird

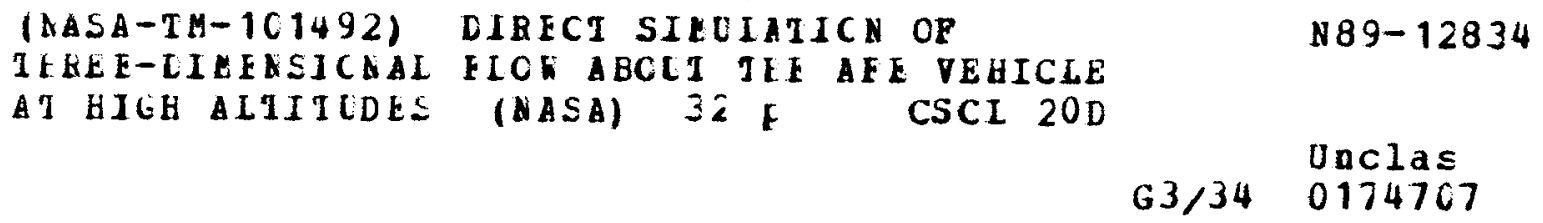

September 1988

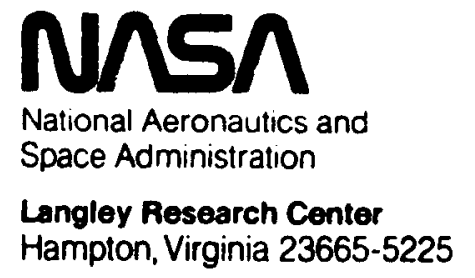




\title{
DIRECT SIMULATION OF THREE-DIMENSIONAL, FLOW \\ ABOUT THE AFE VEHICLE AT HIGH ALTITUDES
}

\author{
M. Cevdet Celenligil \\ Vigyan Research Associates, Inc. \\ Hampton, VA 23666-0325 \\ James N. Moss \\ NASA Langley Research Center \\ Hampton, VA 23665-5225 \\ and \\ Graeme A. Bird \\ The University of Sydney \\ N.S.W. 2006 \\ Australia
}

Abstract

Three-dimensional hypersonic rarefied flow about the Aeroassist Flight Experiment (AFE) vehicle has been studied using the direct simulation Monte Carlo (DSMC) technique. Results are presented for the transitional flow regime encountered between 120 and $200-\mathrm{km}$ altitudes with a reentry velocity of $9.92 \mathrm{~km} / \mathrm{s}$. In the simulations, a five-species reacting real-gas model that accounts for internal energies (rotational and vibrational) is used. The results indicate that the transitional effects are significant even at an altitude of $200 \mathrm{~km}$ and influence the overall vehicle aerodynamics. For the cases considered, the aerodynamic coefficients, surface pressures, convective heating, and flowfield structure variations with rarefaction effects are presented.

\section{Introduction}

Over the past 20 years, increasing attention has been given to aeroassisted flights in which a space vehicle is decelerated and/or 
maneuvered through a planet's atmosphere by making use of aerodynamic forces rather than an all-propulsive system. The objective of these efforts has been to reduce the weight of the propellants carried by the vehicle and to increase the payload. Today, attention has been focused on applying this idea to reusable aeroassisted orbital transfer vehicles (AOTV) which would transfer payloads between two orbits in space. Recently, the National Aeronautics and Space Administration initiated the Aeroassist Flight Experiment (AFE) in order to provide flight data to be used in the design of an AOTV. In this experiment, a subscale model vehicle will be deployed from the Space Shuttle and accelerated by a solid rocket motor to enter the Earth's atmosphere down to an altitude of about $75 \mathrm{~km}$. The vehicle will then exit the atmosphere to be retrieved by the Shuttle. Aerothermal loads will be constantly recorded by the AFE vehicle during this representative flight, which is scheduled for the mid 1990's.'

Today, estimation of the aerothermal loads for the design of an AOTV and the AFE vehicle primarily depends on numerical simulations because ground-based facilities fail to simulate the highly nonequilibrium conditions about these vehicles. After the AFE experiment, the recorded flight data will be used to validate these simulations.

\section{Analysis}

At high altitudes, the mean free path of molecules is comparable with the size of space vehicles, thereby invalidating the use of the NavierStokes equations because the continuum assumptions are not applicable. For these flows, the direct simulation techniques appear to be the most feasible methods from the computational point of view. 
In this study, the direct simulation Monte Carlo (DSMC) method as developed by $B^{2} d^{2}$ is used. This method simulates transitional flows by following the motion of thousands of representative molecules in the flowfield. The molecular motion is computed for small time intervals. Intermolecular collisions appropriate to these time intervals are uncoupled from the molecular motion and are calculated by choosing collision partners on a probabilistic basis. In this study, the collisions are modeled by the variable-hard-sphere (VHS) model, ${ }^{3}$ as is the case with most contemporary DSMC applications. The VHS model treats the molecules as hard spheres, as far as the scattering is concerned, but the collision cross section depends on the relative speed of the colliding partners. A reacting real-gas model with five chemical species $\left(\mathrm{O}_{2}, \mathrm{~N}_{2}, \mathrm{O}, \mathrm{N}\right.$, and $\left.\mathrm{NO}\right)$ is used for these computations. Ionization is neglected on the expectation that it will not be significant for the present conditions.

For computational convenience, the domain is divided into regions, and each region consists of a network of cells. In the three-dimensional DSMC applications, the cells are deformed hexahedra, and each cell is further divided into five tetrahedral subcells. The collision partners are selected from the same tetrahedral subcells (rather than from the same cells) to reduce the distance between the colliding molecules and to improve the results with regard to the conservation of angular momentum. 4

\section{Computational Results}

In this study, flow about the AFE vehicle has been investigated. The shape of the AFE vehicle is that proposed by the NASA Johnson Space Center and is sketched in figure 1 . The vehicle basically consists of a forebody aerobrake, a hexagonal experimental carrier, and a solid rocket motor which 
is ejected prior to atmospheric entry. The axis of the solid rocket motor is inclined at $a 17^{\circ}$ angle with respect to the incoming freestream.

The angle of incidence remains constant for the present solutions. The wind vector was assumed to be parallel to the $x$-axis ( $f$ ig. 1), which corresponds to zero incidence for the present coordinate system. (This is equivalent to an angle of incidence of $17^{\circ}$ for the AFE body axes system in which the $x$-coordinate is coincident with the solid rocket motor axis.)

The forebody of the AFE vehicle is generated by a $60^{\circ}$ elliptic cone raked at a $73^{\circ}$ angle. Its nose is blunted in the shape of an ellipsoid, and the aft skirt is appended such that at each meridional plane it is tangent to the cone by a circle of fixed radius. The base length of the vehicle is $4.25 \mathrm{~m}$. Cheatwood et al. ${ }^{5}$ describe mathematically the shape of the AFE forebody and have written a computer program to generate the forebody surface coordinates. Their program has been incorporated in these computations to describe the forebody surface grid. The coordinate system used in this study is located at the tip of the elliptic cone such that the $x$-axis becomes parallel to the freestream velocity, and the $x-y$ plane is located on the symmetry plane, as shown in figure 1 . According to this system, the geometric stagnation point of the AFE vehicle 1 ies at $x=0.3 \mathrm{~m}$, $y=0, z=0$

In general, calculations for high altitudes need to be performed on large computational domains where the cells can be quite large because the molecular mean free path, and consequently the disturbance field in front of the body, is large. This fact is reflected in the present calculations. For example, the computational domain in front of the body starts at $x=-4.7 \mathrm{~m}$ for the $120-\mathrm{km}-a l t i t u d e$ case, at $\mathrm{x}=-10.3 \mathrm{~m}$ for the $140-\mathrm{km}-$ altitude case, and at $\mathrm{x}=-18 \mathrm{~m}$ for the $150-\mathrm{km}$ and higher altitude cases. 
The 130-km altitude computations show that the afterbody portion does not affect the vehicle aerodynamics, hence for the $140-\mathrm{km}$ and higher altitudes, only the forebody domain is used. For all the calculations, only half of the geometry is considered because of the plane of symmetry.

Figure 2 shows the computational grid used for the 120 -km-altitude case. In this figure, both the cells and subcells are shown on the outer freestream boundary. However, on the plane of symmetry, only the cell structure is drawn for clarity. For all cases considered, the cells and subcells are exactly matched with the neighboring ones throughout the computational domain. For the computations where both the forebody and afterbody are considered (i.e., the 120 and 130-km-altitude cases), a total of 21 regions with 1,820 cells is used, and these flows are simulated using about 55,000 molecules. The forebody domain is divided into 6 regions with 600 cells, and the $140-\mathrm{km}$ and higher altitude cases are simulated using about 20,000 molecules. In all cases, the AFE forebody surface consists of 100 triangles, or in other words, 50 distorted rectangles with 10 divisions in the longitudinal direction (as can be seen from fig. 2) and 5 divisions in the spanwise direction.

At the freestream boundaries, atmospheric conditions appropriate for the particular altitude are used. Table 1 lists the atmospheric conditions for altitudes between 120 and $200 \mathrm{~km}$. The uniform forebody temperature is based on free-mnlecule radiative equilibrium heat transfer to the stagnation point. These values are tabulated in Table 2. The AFE vehicle is insulated with very low conductivity materials. The afterbody wall temperature is, therefore, assumed to be at a uniform $300 \mathrm{~K}$ for all cases. At the body surface, full thermal accommodation with diffuse reflection for the gassurface interaction is assumed. 
Once steady state was achieved in the simulations, computations were continued for an additional 8,000 time steps, and samples were taken every other time step to arrive at the time-averaged results. Examples of the time-averaged results presented in figures 3-12 are based on these 4,000 samples. In figures $3-6$, surface pressure and heat transfer rate distributions are presented. Both pressure and surface heating have their maxima slightly below the geometric stagnation point, are fairly uniformly distributed along the forebody surface (this was one of the design aims), and quickly decrease along the skirt.

Figures 7-9 show various flowfield contours in the $x-y$ plane for the 120-km case. In these figures, the vehicle is half a cell size larger in all directions. The distortion in the picture is greatest in the afterbody where rather large cells are used. Clearly, the flowfield density reaches its maximum at the body surface, whereas the maximum translational (kinetic) temperature occurs somewhere away from the surface in the upstream direction. On the other hand, the internal temperature shows a rather complicated picture and is discussed in the next section.

Figures 10-12 and Table 3 present the aerodynamic coefficients $\left(C_{D}=\right.$ drag coefficient, $C_{L}=1$ ift coefficient, $L / D=1$ ift-to-drag ratio) at selected altitudes for an angle of incidence of $0^{\circ}$ (using the present coordinate system shown in figure 1). The forces are normalized with respect to $1 / 2 \rho_{\infty} U_{\infty}^{2} A_{r e f}$ where $\rho_{\infty}$ and $U_{\infty}$ are the freestream density and velocity, respectively, and $A_{\text {ref }}$, the reference area, equals $14.1 \mathrm{~m}^{2}$. These figures and the table also show the calculated free-molecule and modified Newtonian results, along with experimental wind-tunnel data. The experiments were conducted in the NASA Langley Research Center Mach 10 air 
and Mach $6 \mathrm{CF}_{4}$ (freon) wind tunnels using high-fidelity models. ${ }^{6}$ The windtunnel values presented in Table 3 and figures $10-12$ are recommended values for zero incidence based on the Mach 10 air and Mach $6 \mathrm{CF}_{4}$ results (personal communication from Chris Cerimele, NASA Johnson Space Center). Clearly, the DSMC results approach the free-molecule limit very slowly at higher altitudes, and even at an altitude of $200 \mathrm{~km}$, the flow is not completely collisionless. Prior to this study, it was generally acknowledged that free-molecule flow existed for the AFE vehicle for altitudes near $150 \mathrm{~km}$, but this study shows that the transitional effects are significant at these altitudes and influence the overall aerodynamic coefficients. These results have important implications for the interpretation of aerodynamic coefficients extracted from flight measurements under rarefied conditions. Figures 10-12 also contain the results of the Lockhecd bridging formula which empirically connects the axial and normal aerodynamic force coefficients between the continuum and free-molecule limits. This is accomplished with a sine-square function by assuming continuum flow at a Knudsen number $K n_{\infty}=0.01$ and free-molecule flow at $K n_{\infty}=10$, which correspond to altitudes of 90 and $150 \mathrm{~km}$, respectively. The bridging formula results are plotted to show the general trend even though its results are erroneous for the conditions considered in the present study. Figures 10 and 11 also show effects of the pressure and shear forces on the total drag and lift coefficients. Clearly, the pressure contributions are fairly constant at all altitudes and are approximately equal to the measured continuum wind-tunnel values. However, the shear contribution increases with altitude, and in effect, increases the drag and reduces the lift. The pressure coefficient at the stagnation point is 1.944 for the $120-\mathrm{km}$ case 
and 2.033 for the $200-\mathrm{km}$ case. The corresponding limiting value for the continuum regime is 1.839 , and the free-molecule result is 2.051 .

One of the design aims of the AFE was to have the vehicle trim at $17^{\circ}$ angle of attack. At this attitude, therefore, the pitching moment should be zero. The computed pitching moment coefficients with respect to the center of gravity are less than $10^{-2}$, and unlike the drag and lift, are expected to be sensitive to the surface grid chosen. Considering the relative coarseness of the grid and the scatter due to the small sample, it is more meaningful to report the equation of the line along which the resultant force acts. For the $120-\mathrm{km}$ case, this line is $\mathrm{y}=0.07 \mathrm{x}-1.031$ according to the coordinate system shown in figure 1 and varies smoothly with altitude to $y=0.013 x-0.984$ for the $200-k m$ case.

\section{Discussion}

The computations in this study have been performed using a general 3-D DSMC computer program written by G. A. Bird. This program has already been applied to various wedge flow problems by the present authors. 7 Threedimensional DSMC applications have recently become possible through advancements in computer technology, and various cylinder/cone problems have been studied by other groups as well. 8 However, this is the first time that a general 3-D DSMC code has been used to describe the flow about a fullscale space vehicle.

The first problem investigated in this study was the case where the AFE vehicle is represented by an idealized axisymmetric geometry. This case was previously studied using an axisymmetric DSMC code for an altitude of $130 \mathrm{~km}$ and below. ${ }^{9}$ Therefore, initial application of the 3-D program concentrated on the axisymmetric flow problem at $130 \mathrm{~km}$ because higher altitude flows 
are, in general, easier to compute. The calculated results were in very good agreement with those of the axisymmetric code computations. The grid used in the 3-D computations ( 8 divisions along the surface and 16 divisions in the normal direction) was coarser than the one used in the axisymmetric program (20 divisions along the surface and 40 divisions in the normal direction), and the cell structuring was different. Agreement of these results, consequently, is an indication of grid independency for the computations. For this case, the extent of the computational domain was also checked. When the domain was started $5 \mathrm{~m}$ in front of the body (where density ratio $\rho / \rho_{\infty}=1.5$ and translational temperature $T_{\text {tr }}=17,000 \mathrm{~K}$ ) instead of $15 \mathrm{~m}$ (where $\rho / \rho_{\infty}=1.0$ and $T_{t r}=1,500 \mathrm{~K}$ ), the results showed almost no difference.

Subsequently, the 3-D program was applied to the three-dimensional flow about the actual $A F E$ vehicle at $130 \mathrm{~km}$, first wi thout and then with the afterbody. It should be noted that the three-dimensional shape of the AFE vehicle is exactly generated without any approximations. In the computations, only the forebody and the experimental carrier were included because the solid rocket motor is ejected during entry near $130 \mathrm{~km}$. Above this altitude the afterbody has no effect on the aerodynamics. The experience accumulated on the $130-\mathrm{km}$ altitude case has been used for the other altitude computations, and only one computation has been performed for each of those cases. Nevertheless, in all of those computations, the basic DSMC requirements are satisfied. Namely, the cell sizes are smaller than the local mean iree path, the number of molecules in each cell is of order 10, and the time step used to move the molecules is smaller than the mean collision time per molecule. Past experience indicates that these results will not differ if finer grids are used. 
In analyzing these results, one has to remember that these flows are in a highly nonequilibrium state and that these macroscopic properties are obtained by averaging over varinus classes of molecules whose distribution functions are widely separated in velocity space. Therefore, it is not possible to properly interpret these kinetic temperature contours entirely from the viewpoint of classical thermodynamics.

The complicated internal energy distribution shown in figure 9 is due to the three distinct classes of molecules present in the flowfield. First of all, at these altitudes there are quite a few freestream molecules with low internal energies crossing the entire domain without any collisions. Second, there is the effect of intermolecular collisions. Although there are very few collisions, the internal energies of the molecules which have undergone a collision are altered drastically because of the energy exchange with the high translational energies of the gas molecules. Third, there are molecules that have been reflected from the body surface. These molecules have low internal energies because the surface temperature is low, and it is assumed that these molecules are reflected with full thermal accommodation. The relative abundance of these three classes of molecules varies with location in the flowfield, and their mixing produces a highly nonequilibrium flow. Figure 9 shows the effects of this on the macroscopic flowfield properties. As the flow approaches the body along the stagnation streaml ine, the average internal energy first increases as a result of intermolecular collisions and then decreases because of the increase in the concentration of surface-reflected molecules. As the molecules move around the body, they have more opportunity to have collisions, and since the relative abundance of the collided molecules increases, so does the average internal energy. In the wake region, the molecular number density is 
extremely small due to the "shadow effect" of the forebody. Consequently, this region has basically one class of molecules, and they are the ones which have undergone a collision. Because this class of molecules has high internal energies, the average internal energies in the wake region tend to be higher.

As the aliitude increases to $200 \mathrm{~km}$, the internal temperature picture changes entirely. This is not surprising, because at this altitude the freestream temperature is higher, the body surface temperature is cooler (see Tables 1 and 2), and more importantly, the number of intermolecular collisions is much lower. In other words, the flowfield has basically two classes of molecules, namely, freestream and surface-reflected molecules. With full thermal accommodation, the surface-reflected molecules have low internal energies due to the cool surface temperature, and naturally, their concentration is high near the body. Consequently, the average internal energy in the forebody region continuously decreases as the flow approaches the body.

For $10 \mathrm{~km} / \mathrm{s}$ flows under highly rarefied conditions, the assumption of full thermal accommodation is almost certainly incorrect. As stated before, for most cases considered in this study, there are quite a few freestream molecules which hit the body surface with very large translational energies. According to the full thermal accommodation assumption used in this study, all of the energy of the molecules is converted to surface heating, and the molecules are reflected with low internal energy that is characteristic of the surface temperature. However, this assumption is probably unrealistic, and it is quite likely that some of the translational energy appears in excited internal modes during surface reflection. Actually, this phenomenon has already been observed on the Shuttle Orbiter. ${ }^{10}$ Unfortunately, the 
mechanism underlying this complicated interaction and the nature of the energy exchange are not known. These questions need to be clarified in future experiments. Until then, the internal temperature results of this study should be interpreted with reservation. At lower altitudes, this phenomenon is less significant because the molecules which hit the surface have less translational energy due to intermolecular collisions. Even though the nature of the gas-surface interaction could significantly alter the internal temperatures, it should not affect the translational temperatures and the aerodynamic coefficients because the translational energy is most likely fully accommodated to the surface.

\section{Summary and Conclusions}

This study applies the direct simulation Monte Carlo technique to assess the three-dimensional flow about the Aeroassist Flight Experiment (AFE) vehicle. For altitudes of 120 to $200 \mathrm{~km}$, results show that:

(1) The flow approaches the free-molecule limit very gradually at higher altitudes, and even at $200 \mathrm{~km}$, the flow is not completely collisionless.

(2) Maximum surface pressure and heating occur slightly below the geometric stagnation point of the vehicle.

(3) At altitudes of $130 \mathrm{~km}$ and above, the effect of the AFE afterbody on the vehicle aerodynamics is negligible.

(4) Dissociation is negligible.

This is the first time that the actual three-dimensional flow about the $A F E$ vehicle has been studied at altitudes of $120 \mathrm{~km}$ and above. For the cases investigated, radiation is negligible and is not considered. At these altitudes, the aerothermal loads on the vehicle are small, and the peak 
loads and heating occur at much lower altitudes. This should not overshadow the significance of the present study because these results are the first 3-D solutions to the AFE flow problem in the transitional regime, and they show that the transitional effects are significant even up to an altitude of $200 \mathrm{~km}$. Results such as these are essential for the proper interpretation of the high-altitude aerodynamic measurements.

\section{Acknowledgments}

The authors wish to express their thanks to Robert Blanchard and Jim Jones for their many suggestions, and to Neil Cheatwood for the use of his computer program in generating the forebody surface grid.

\section{References}

${ }^{1}$ walberg, G. D., Siemers, P. M. III, Calloway, R. L., and Jones, J. J., "The Aeroassist Flight Experiment," 38 th International Astronautical Federation Congress, Paper No. IAF-87-197, October 10-17, 1987.

2Bird, G. A., Molecular Gas Dynamics, Clarendon Press, Oxford, 1976.

Bird, G. A., "Monte-Carlo Simulation in an Engineering Context," AIAA Progress in Astronautics and Aeronautics: Rarefied Gas Dynamies, Vol. 74 , Part 1, edited by Sam S. Fisher, 1981, pp. 239-255.

"Bird, G. A., "Direct Simulation of Gas Flows at the Molecular Level," Communications in Applied Numerical Methods, Vol. 4, 1988, pp. 165-172.

${ }^{5}$ Cheatwood, MoNeil F., DeJarnette, Fred R., and Hamilton, H. Harris II, "Geometrical Description for a Proposed Aeroassist Flight Experiment Vehicle," NASA TM-87714, July 1986.

${ }^{6}$ Wells, W. L., "Wind Tunnel Preflight Test Program for Aeroassist Flight Experiment," AIAA Paper 87-2367-CP, August 1987. 
${ }^{7}$ Celenligil, M. C., Bird, G. A., and Moss J. N., "Direct Simulation of Three-Dimensional Hypersonic Flow About Intersecting Blunt wedges," AIAA Paper 88-0463, January 1988.

${ }^{8}$ Riedelbauch, S., Wetzel, W., Kordulla, W., and Oertel, H., Jr., "On the Numerical Simulation of Three-Dimensional Hypersonic Flow," AGARD Conference Preprints No. 428, 1987.

${ }^{9}$ Dogra, V. K., Moss, J. N., and Simmonds, A. L., "Direct Simulation of Aerothermal Loads for an Aeroassist Flight Experiment Vehicle," AIAA Paper 87-1546, June 1987 .

10 Mende, S. B., "Experimental Measurement of Shuttle Glow," AIAA Paper 840550, January 1984 . 
Table 1. Freestream conditions.

Mole fractions

\begin{tabular}{|c|c|c|c|c|c|c|c|}
\hline \multirow[b]{2}{*}{$\begin{array}{l}\text { Altitude, } \\
\mathrm{km}\end{array}$} & \multirow[b]{2}{*}{$\begin{array}{c}\text { Density, } \\
\mathrm{kg} / \mathrm{m}^{3} \\
\times 10^{9}\end{array}$} & \multirow[b]{2}{*}{$\begin{array}{c}\text { Temperature, } \\
\mathrm{K}\end{array}$} & & \multirow[b]{2}{*}{ Mean } & \multirow[b]{2}{*}{$\underset{m}{\text { free path, }}$} \\
\hline & & & $\mathrm{x}_{\mathrm{O}_{2}}$ & $\mathrm{x}_{\mathrm{N}_{2}}$ & $x_{0}$ & & \\
\hline 200 & 0.3 & 1026 & 0.031 & 0.455 & 0.514 & & 197.00 \\
\hline 170 & 0.9 & 892 & 0.044 & 0.548 & 0.408 & & 75.61 \\
\hline 150 & 2.1 & 733 & 0.055 & 0.616 & 0.330 & & 30.93 \\
\hline 140 & 3.9 & 625 & 0.062 & 0.652 & 0.286 & & 16.92 \\
\hline 130 & 8.2 & 500 & 0.071 & 0.691 & 0.238 & & 7.72 \\
\hline 120 & 22.6 & 368 & 0.085 & 0.733 & 0.183 & & 2.69 \\
\hline
\end{tabular}

Table 2. AFE forebody wall temperatures used in the computations.

\begin{tabular}{cc} 
Altitude, & $T_{\text {wall, }}$ \\
\hline $\mathrm{Km}$ & 230 \\
\hline 200 & 300 \\
170 & 370 \\
150 & 425 \\
140 & 500 \\
130 & 650 \\
\hline
\end{tabular}


Table 3. Aerodynamic coefficients.

\begin{tabular}{|c|c|c|c|}
\hline $\begin{array}{c}\text { Altitude, } \\
\mathrm{km}\end{array}$ & $C_{D}$ & $C_{L}$ & $\mathrm{~L} / \mathrm{D}$ \\
\hline \multicolumn{4}{|l|}{ Calculated } \\
\hline (Free molecule) & 1.97 & 0.019 & 0.010 \\
\hline 200 & 1.95 & 0.025 & 0.013 \\
\hline 170 & 1.93 & 0.035 & 0.018 \\
\hline 150 & 1.90 & 0.049 & 0.025 \\
\hline 140 & 1.87 & 0.064 & 0.034 \\
\hline 130 & 1.84 & 0.086 & 0.046 \\
\hline 120 & 1.80 & 0.125 & 0.070 \\
\hline (Modified Newtonian) & 1.24 & 0.338 & 0.274 \\
\hline \multicolumn{4}{|l|}{ Experimental } \\
\hline (Wind tunnel) & 1.35 & 0.381 & 0.281 \\
\hline
\end{tabular}




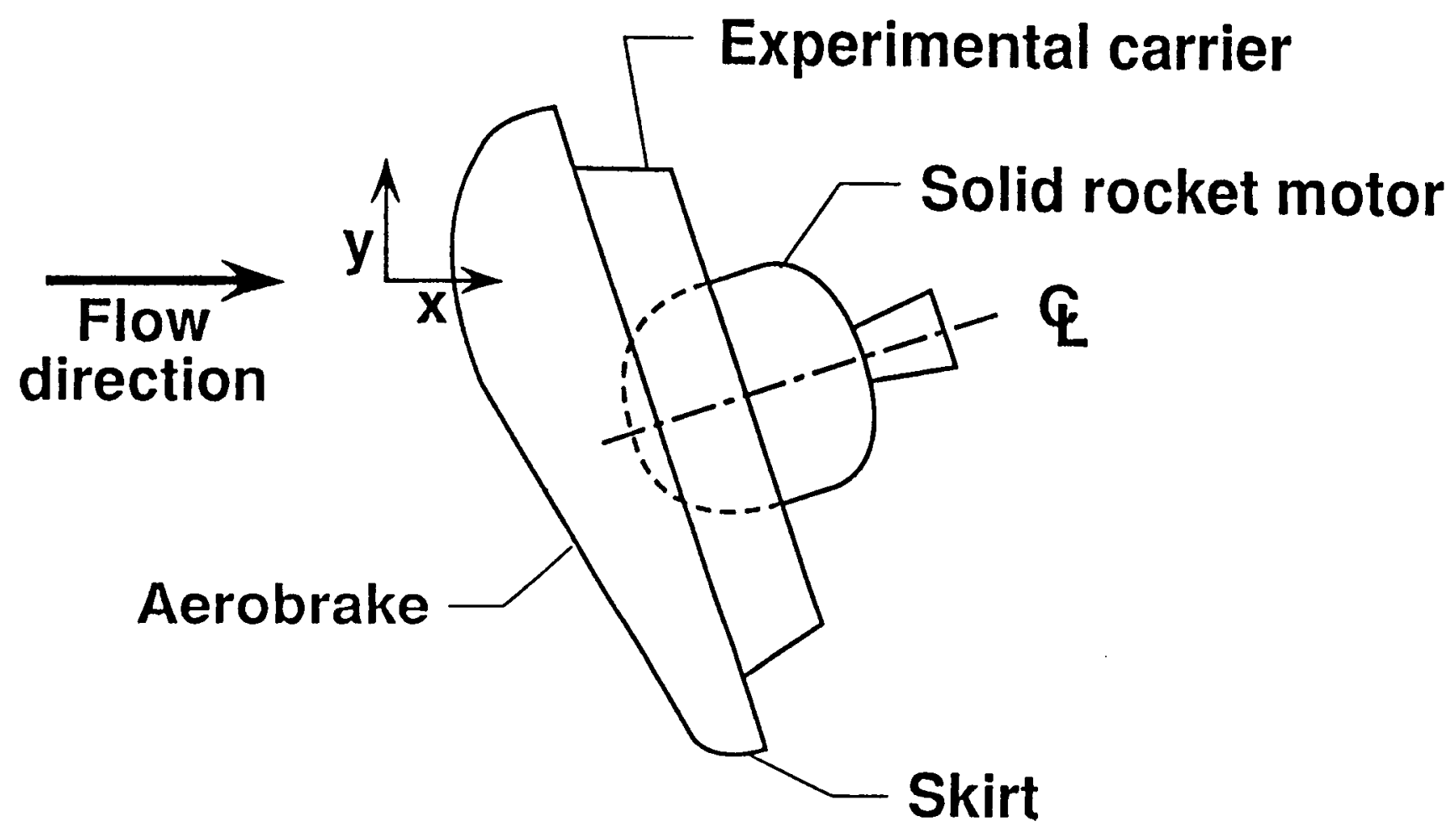

Figure 1. The AFE vehicle. 


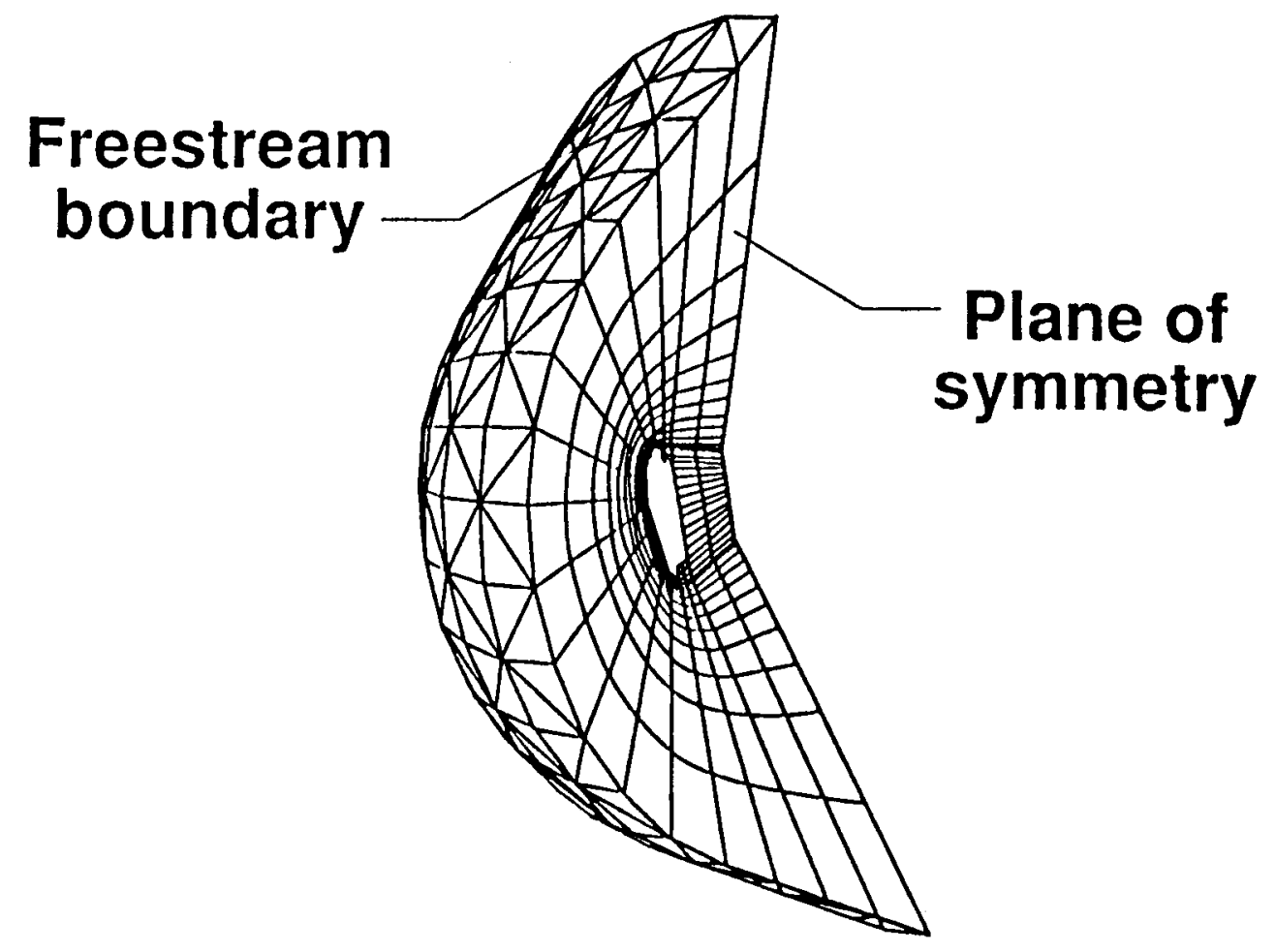

Figure 2. Computational grid (Altitude $=120 \mathrm{~km}$ ). 

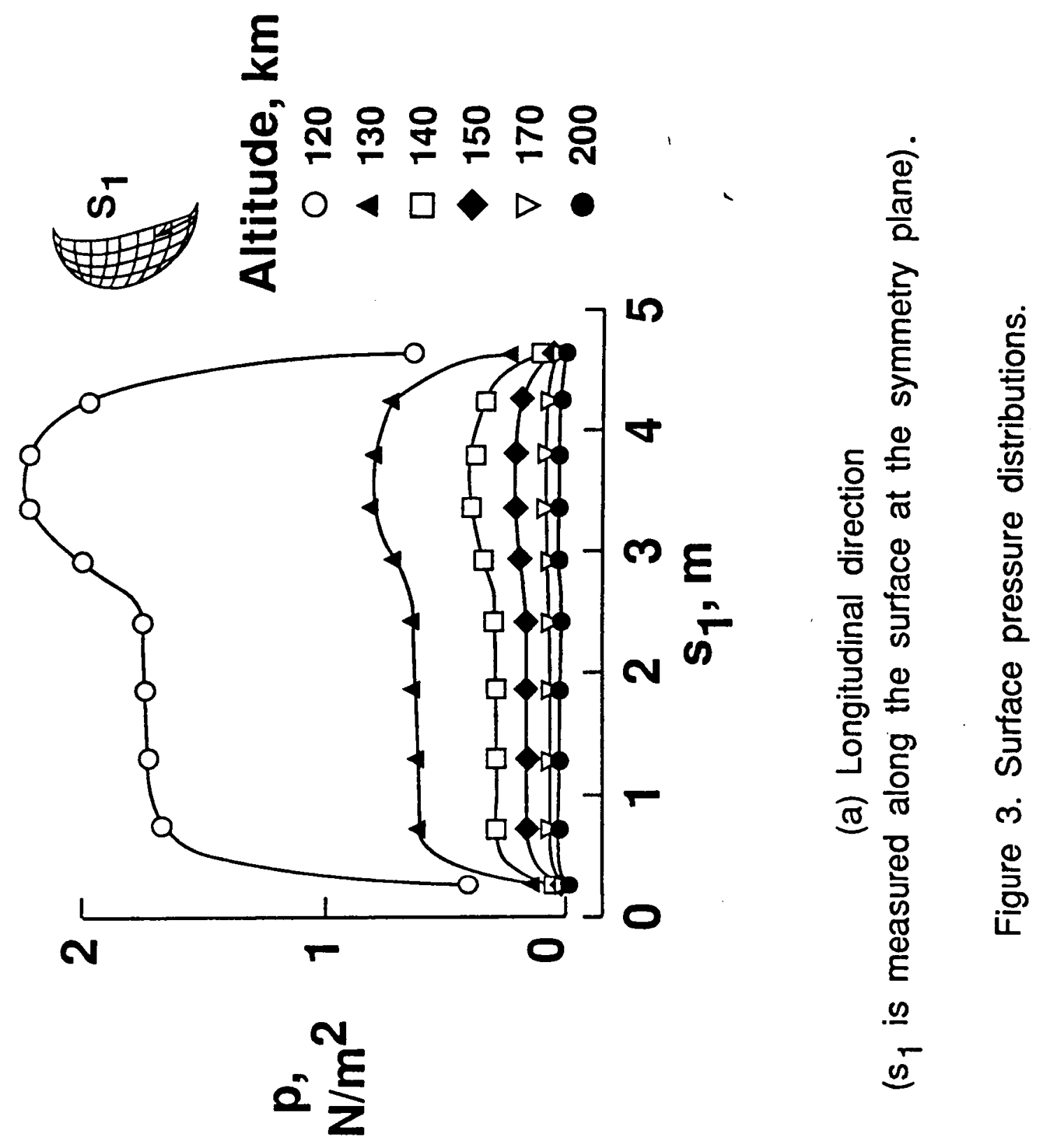

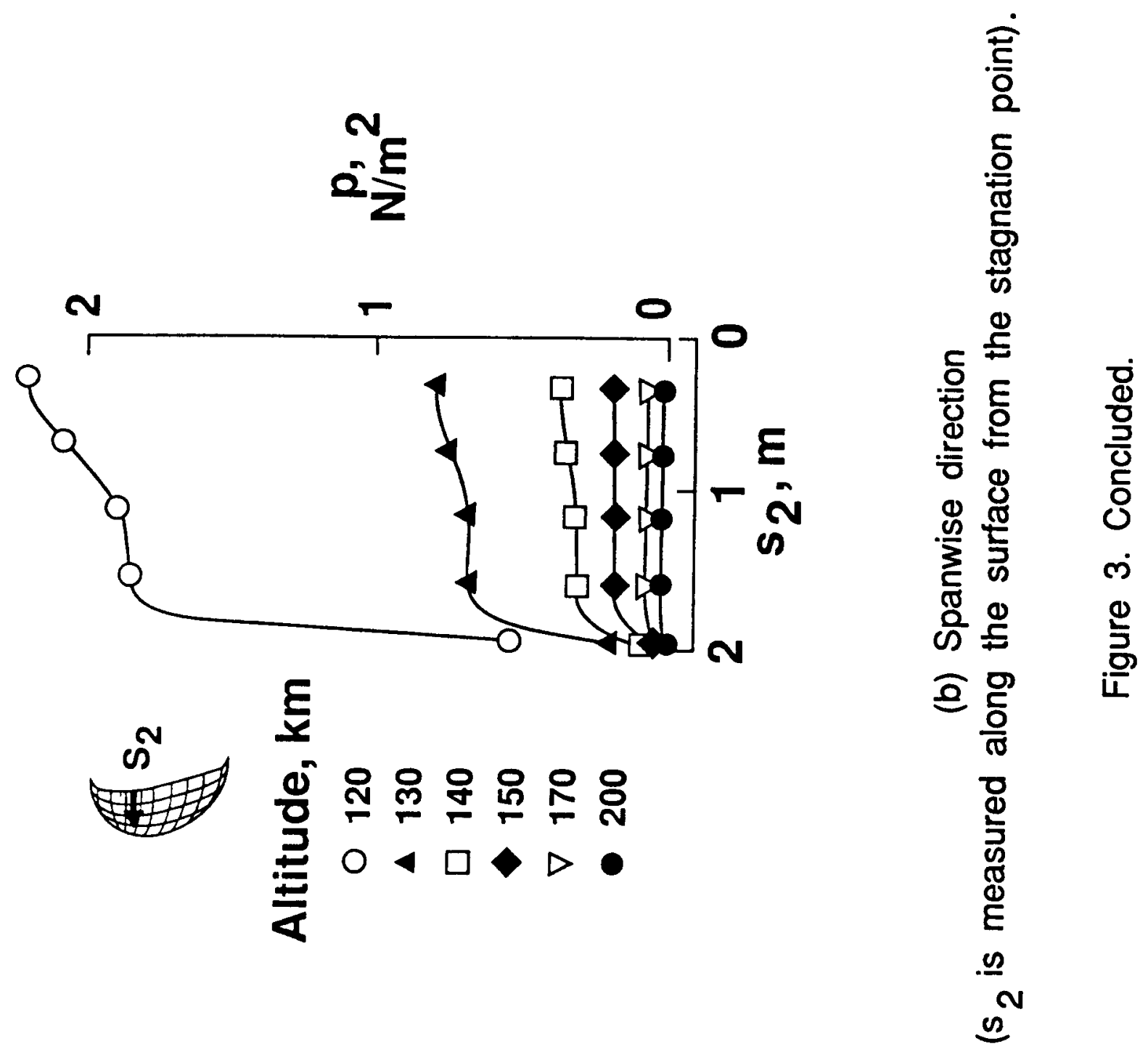


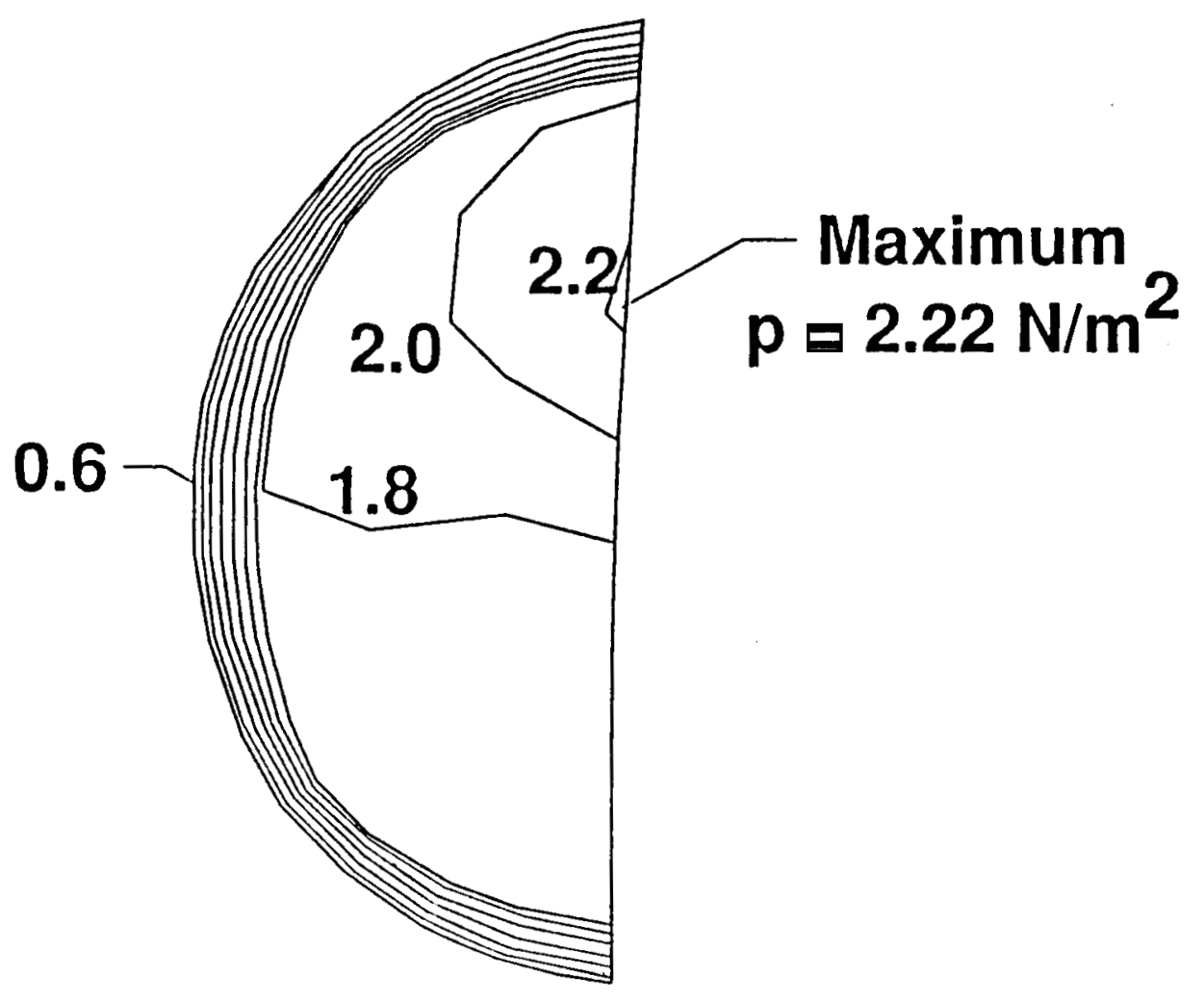

Figure 4. Surface pressure contours

(Altitude $=120 \mathrm{~km})$. 

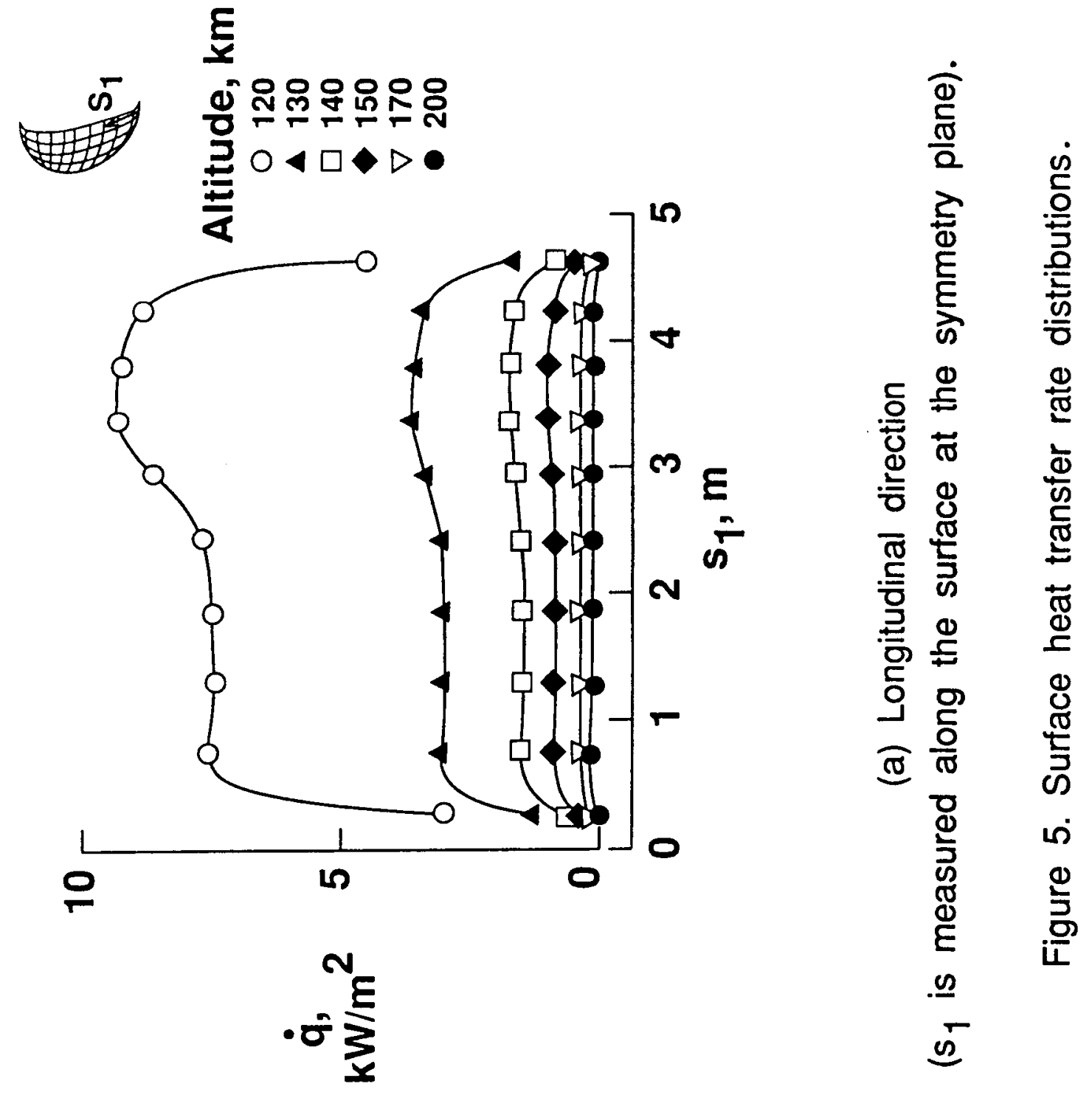


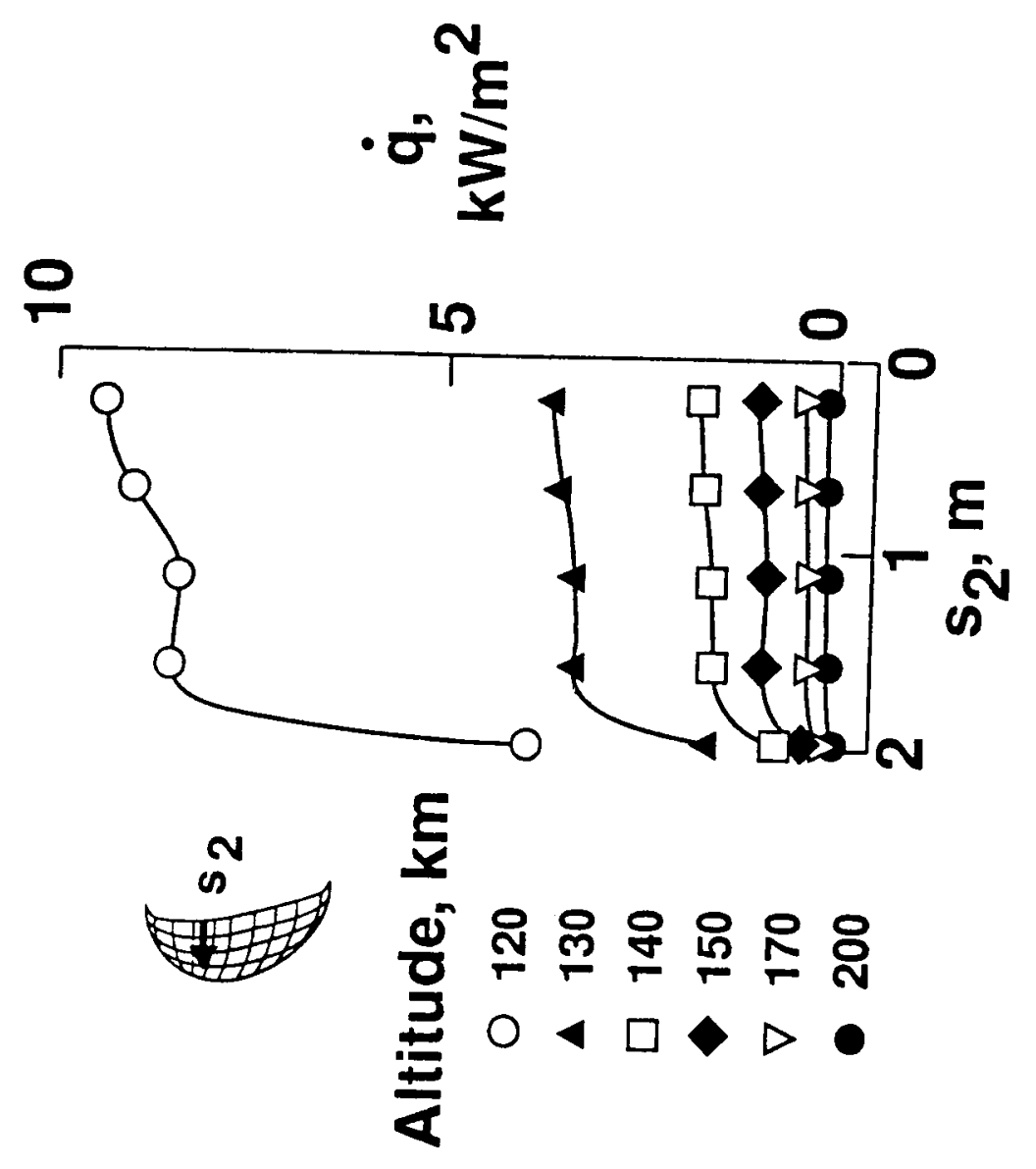

흥

호휴.

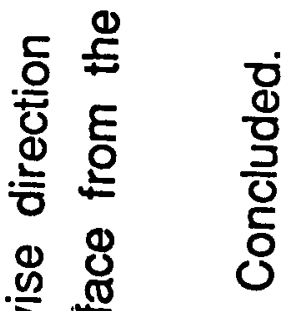

突卷

ஸे ฏ

응

정

.9

e 


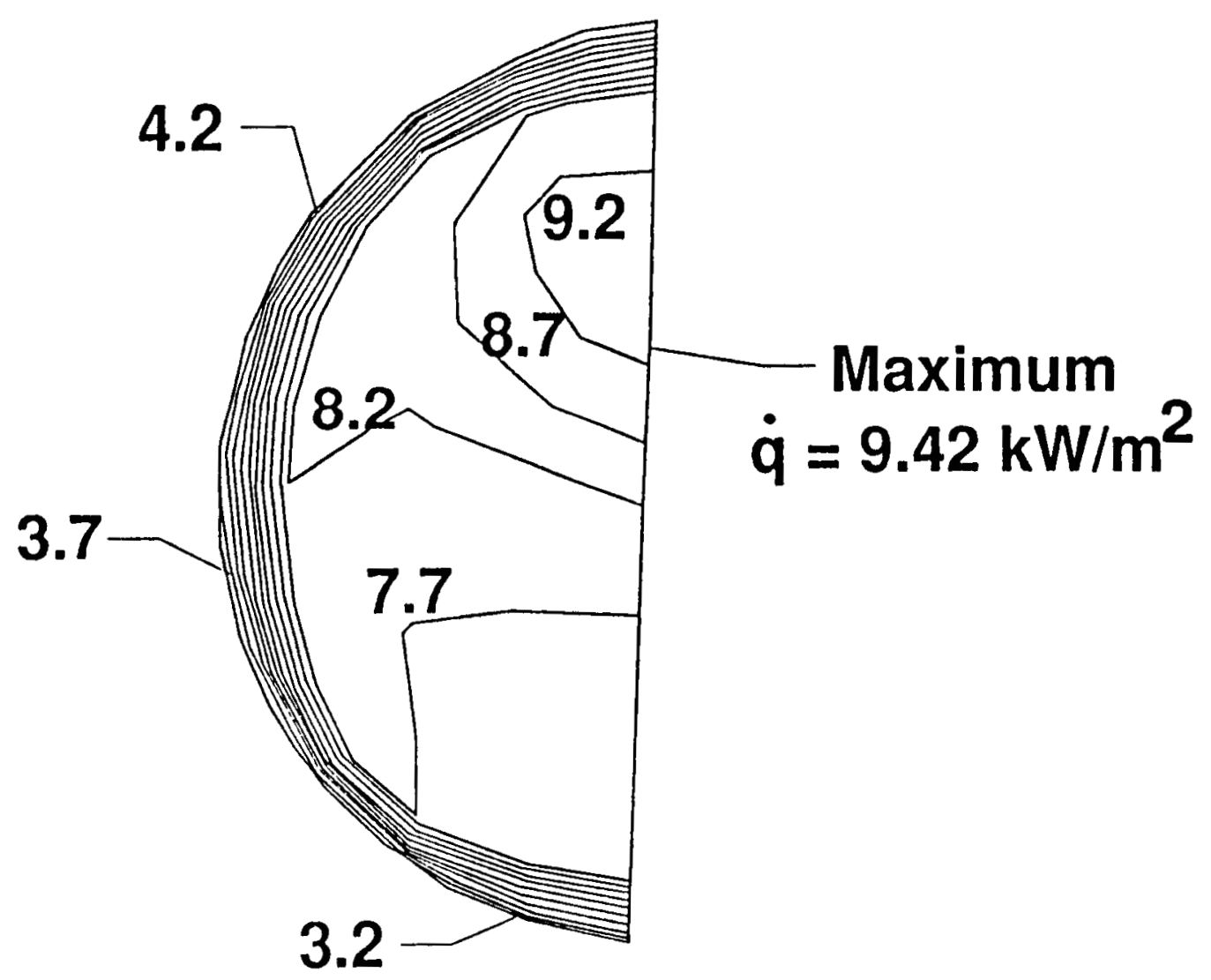

Figure 6. Surface heat transfer rate contours (Altitude $=120 \mathrm{~km}$ ). 


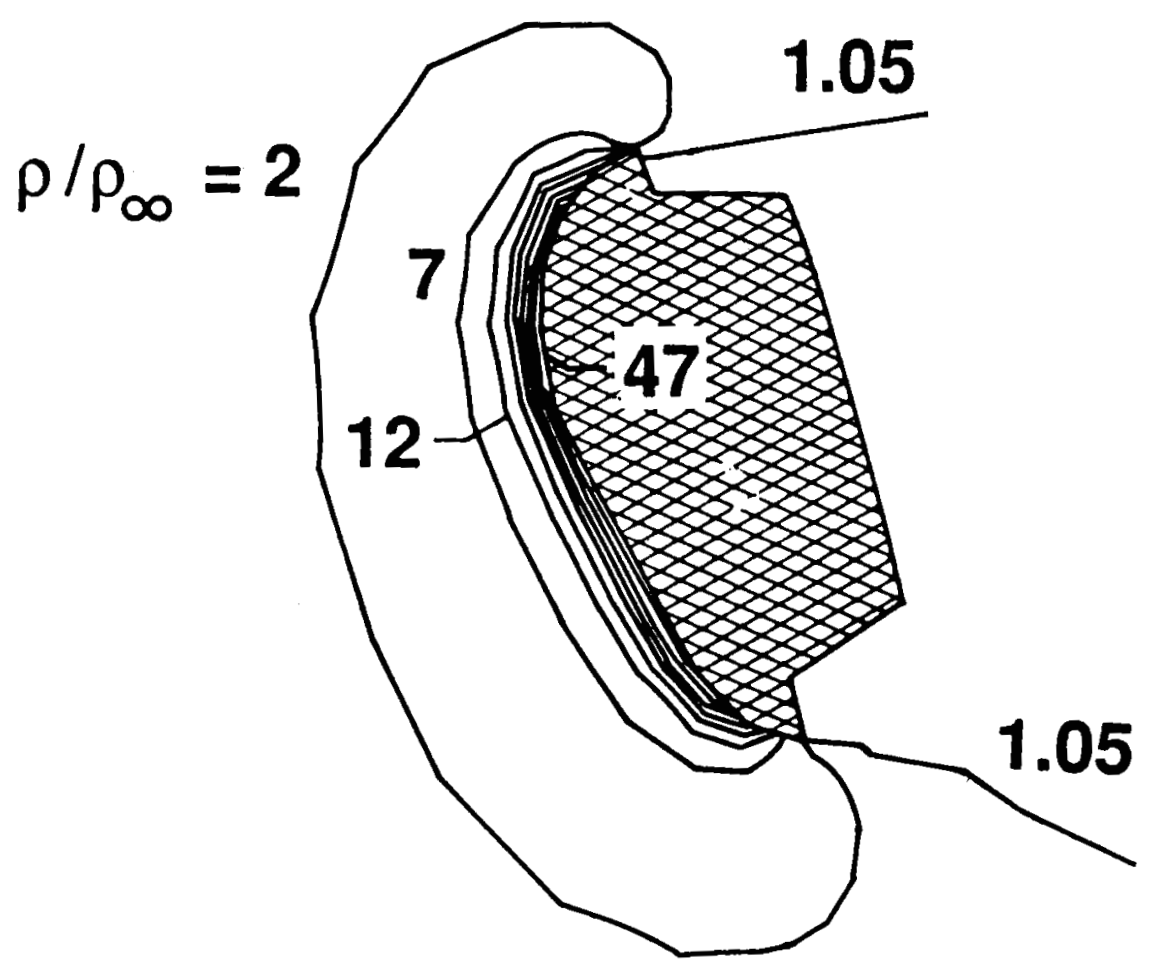

Figure 7. Flowfield density contours at the symmetry plane (Altitude $=120 \mathrm{~km}$ ). 


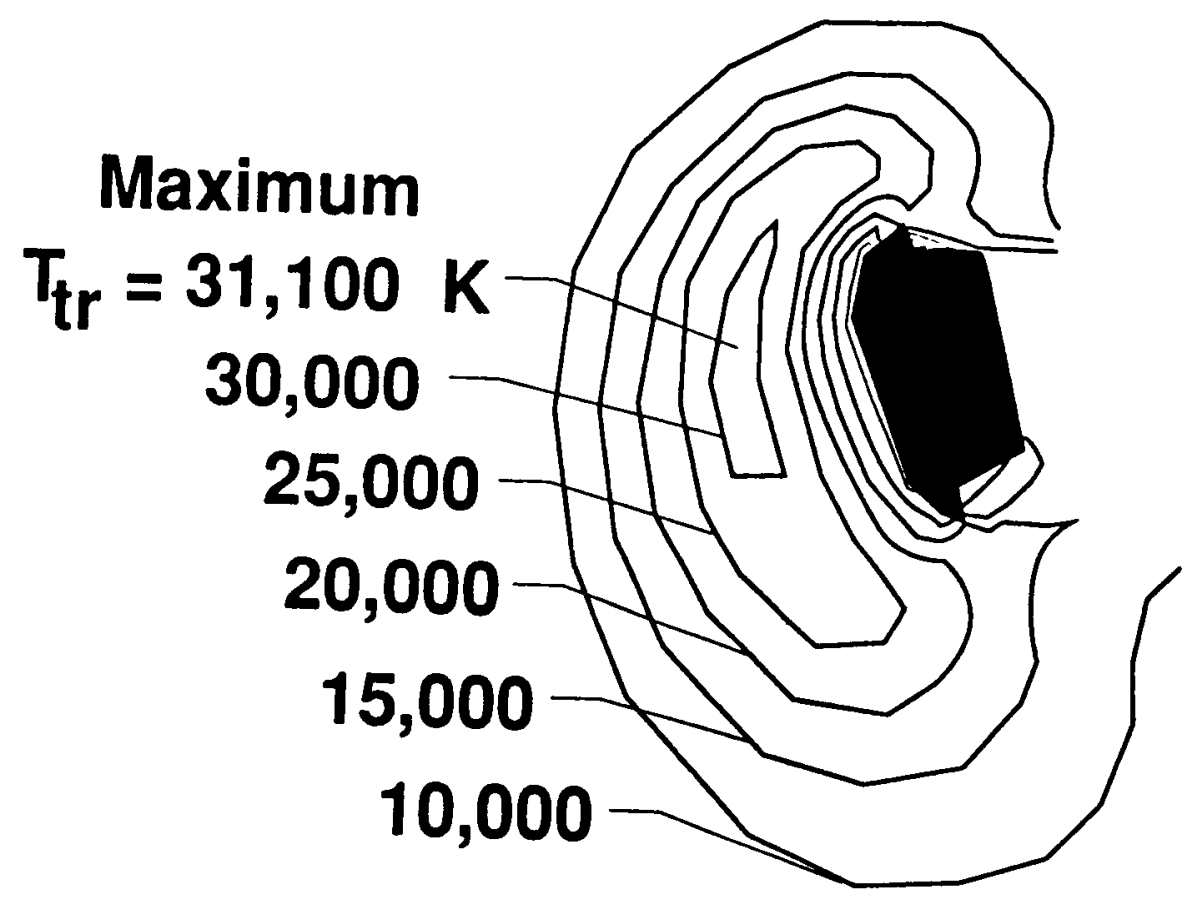

Figure 8. Flowfield translational temperature contours at the symmetry plane (Altitude $=120 \mathrm{~km}$ ). 


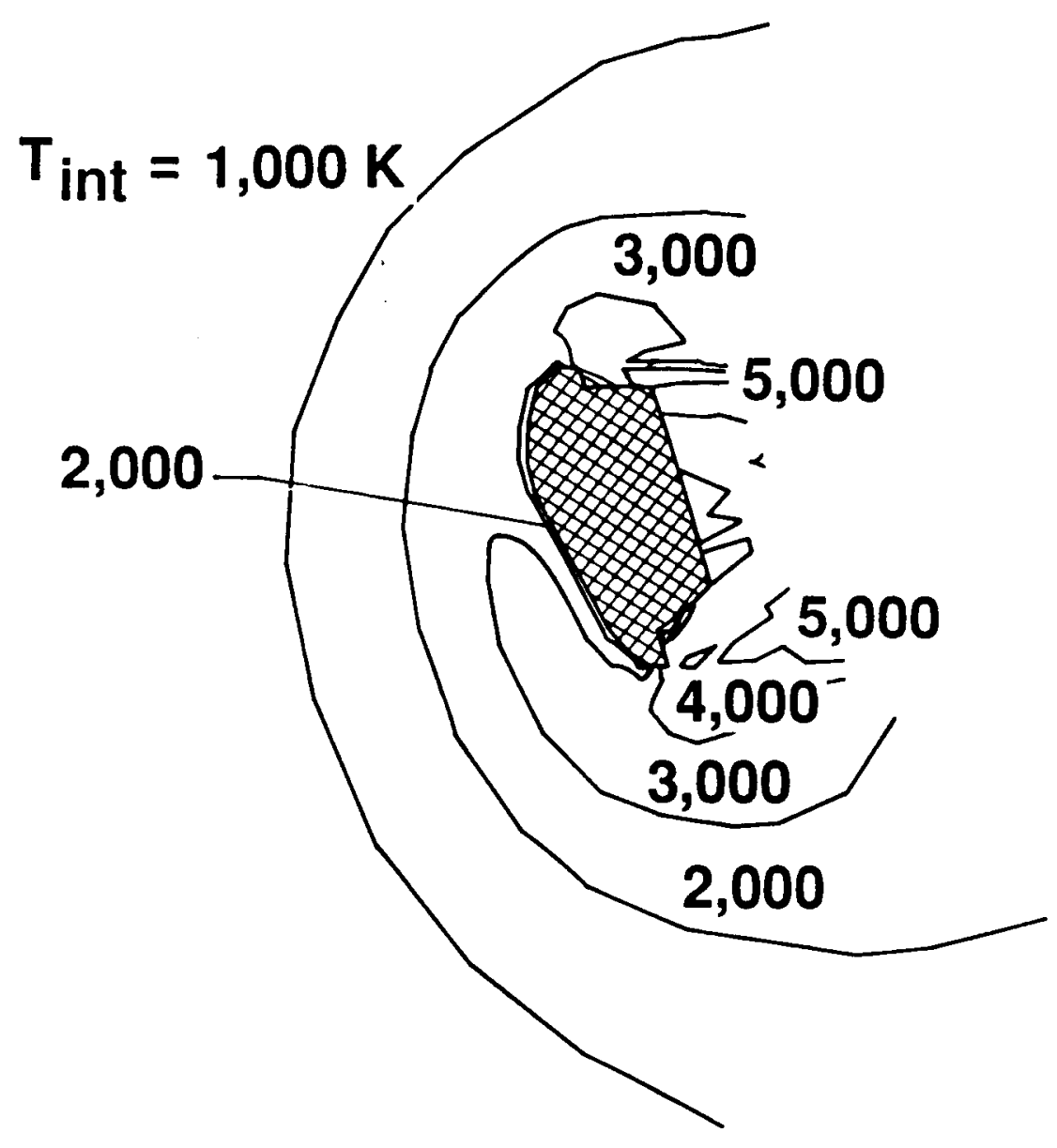

Figure 9. Flowfield internal temperature contours at the symmetry plane (Altitude $=120 \mathrm{~km}$ ). 


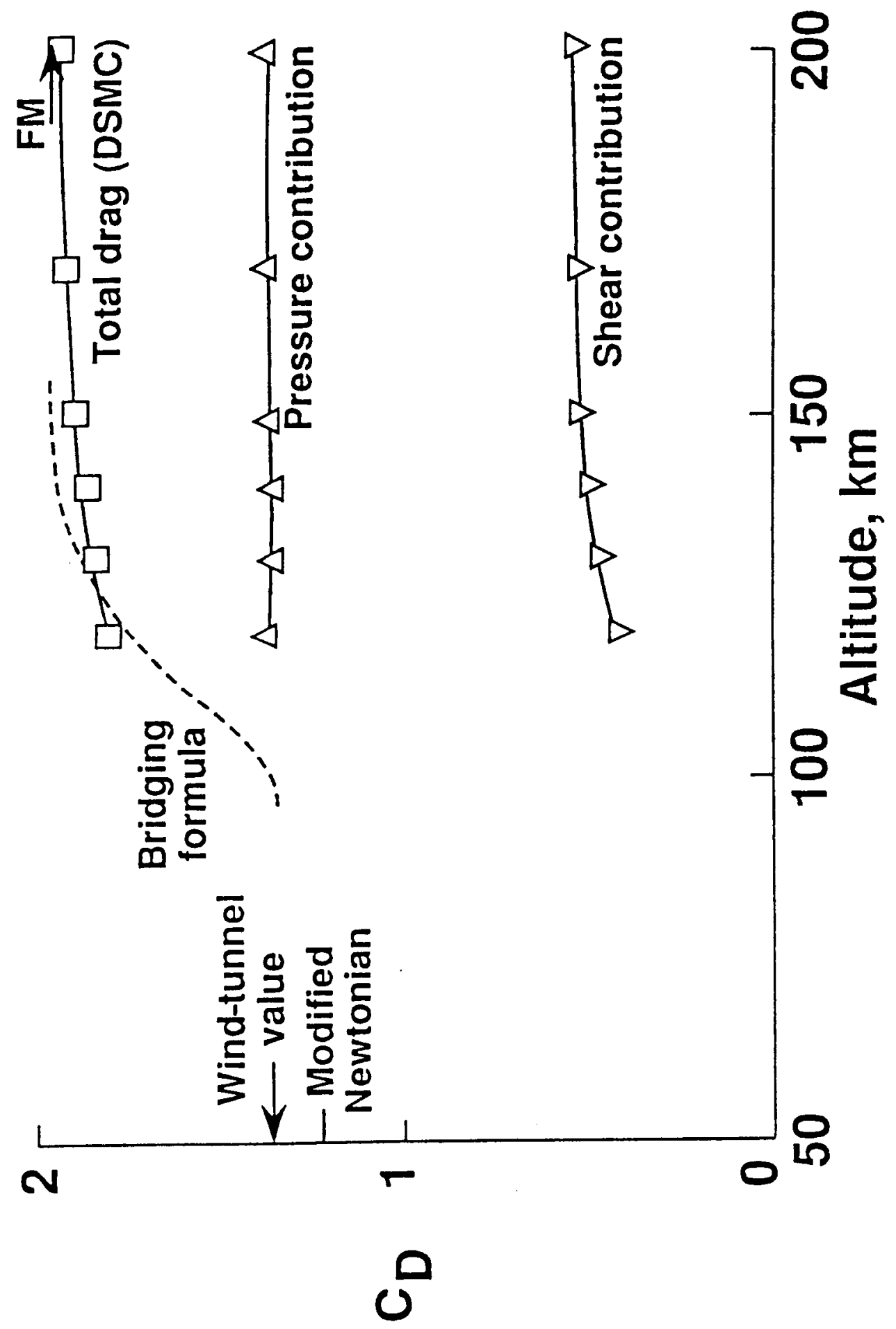

$\frac{0}{3}$

응 는

E

()

屯

क $\sum^{\pi}$

은 능

बั

느를

๑

일

里

돌 $\frac{\Phi}{3}$

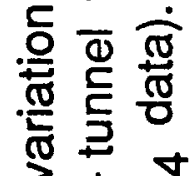

$>\div 4$

등

过

\&

얼

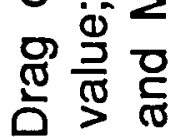

i

음 


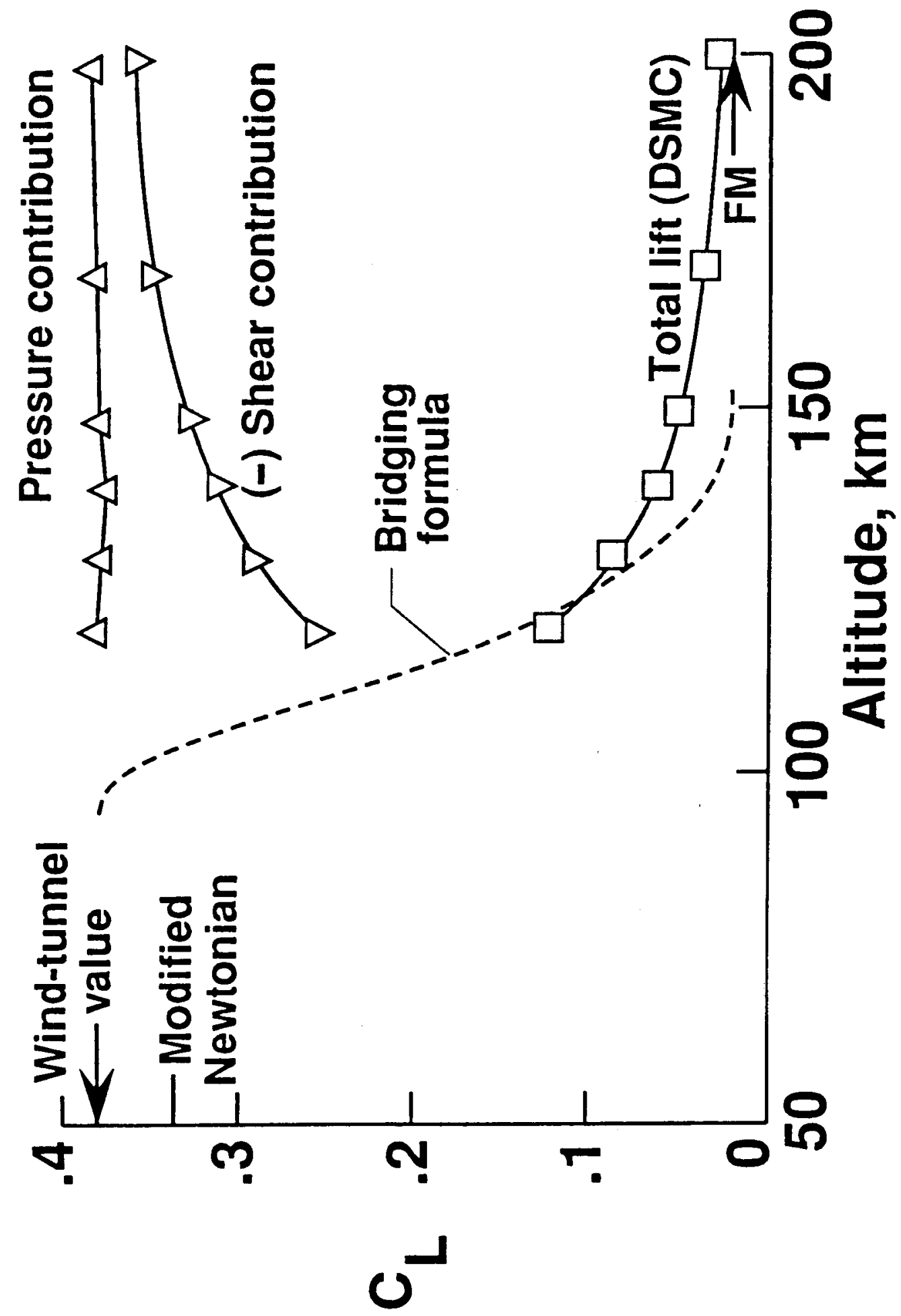

号 는

ब

을 우

i)

$\Phi$

\&

웅

兘 $\frac{9}{5}$

느응

옹

로

$\pm$

兵

동

은

은

ธัช

도

은

幽

엉 을

声

$\approx$

옥 

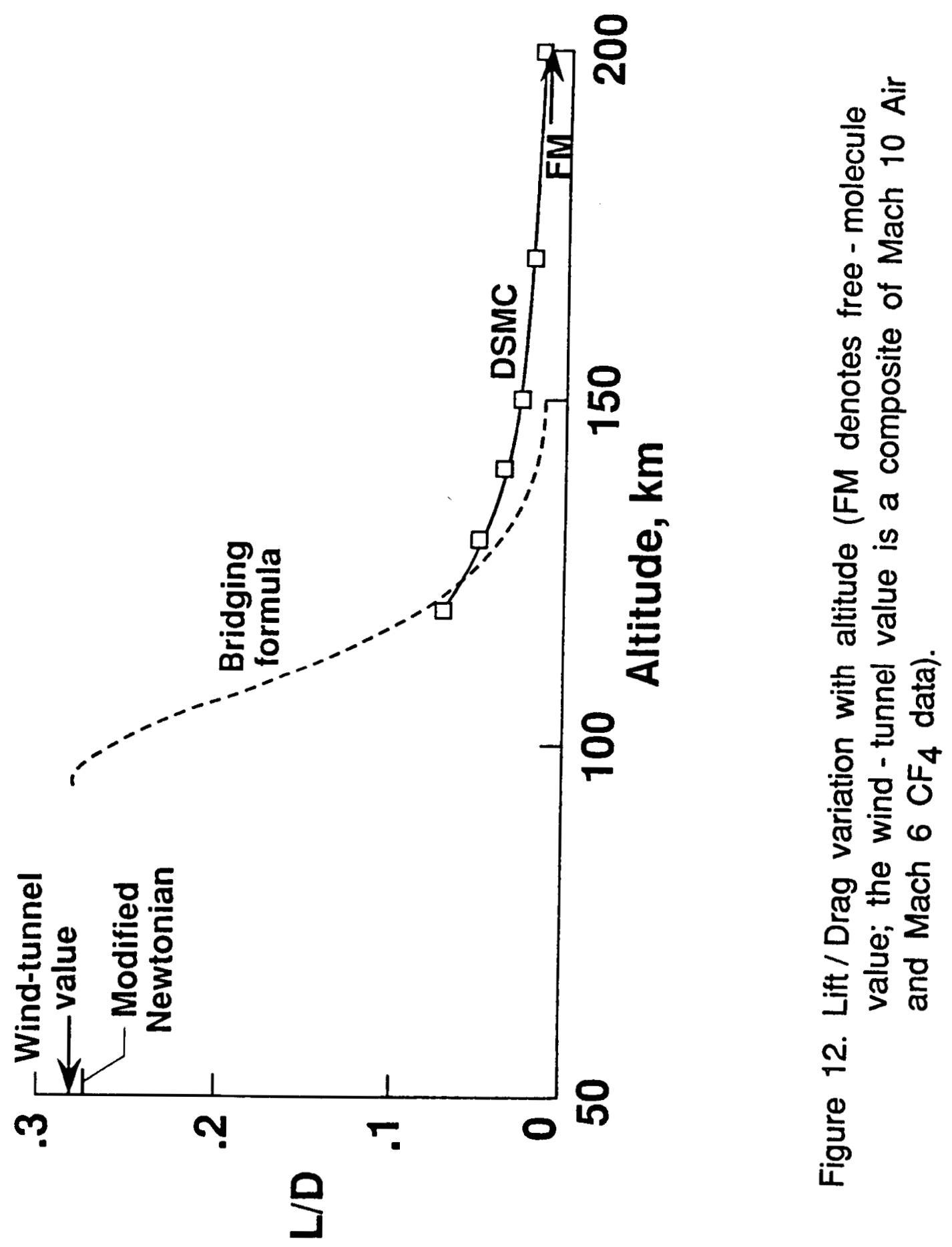


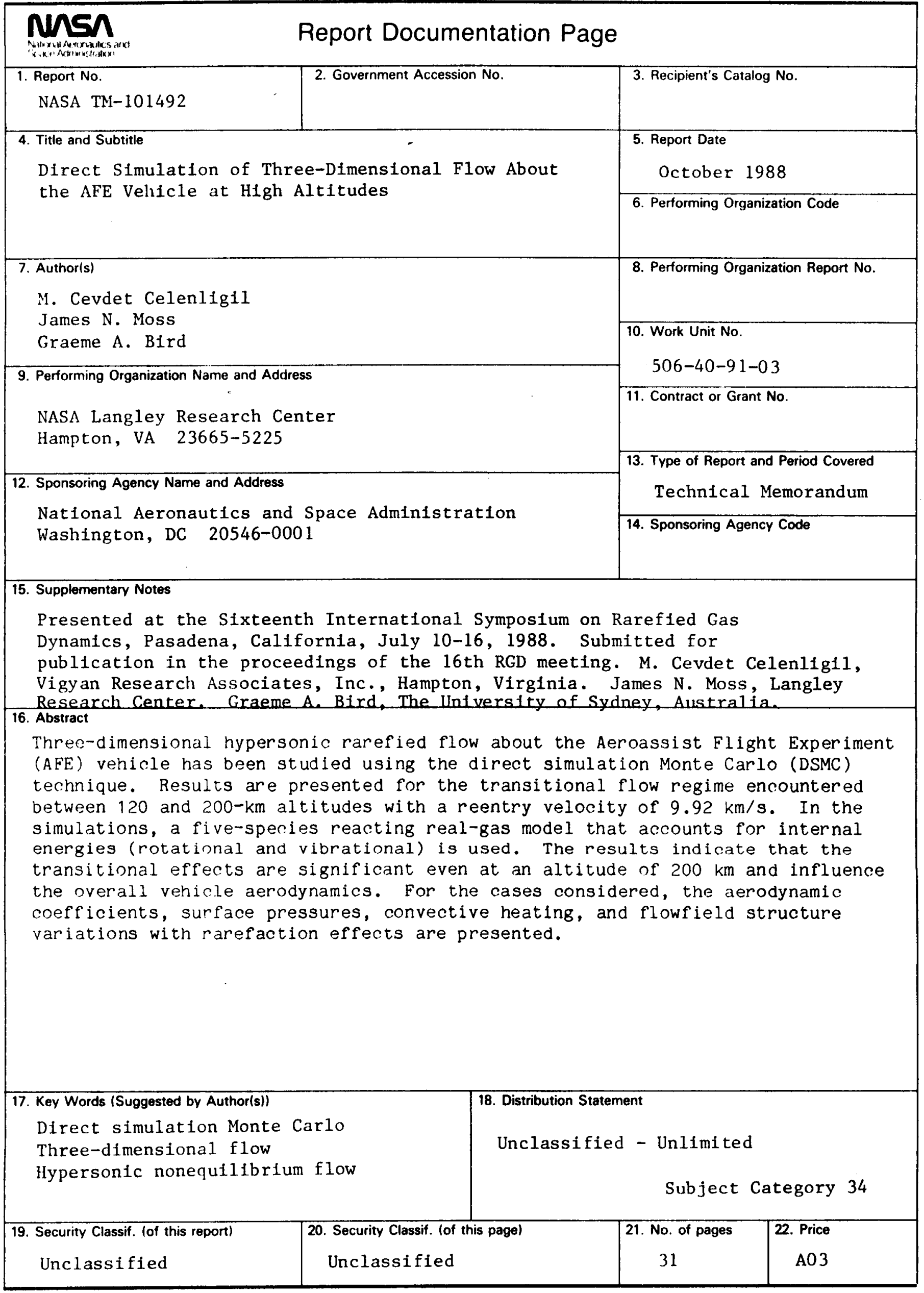

